\title{
Novel method using small-caliber endoscope and balloon overtube for removing gastrointestinal residue
}

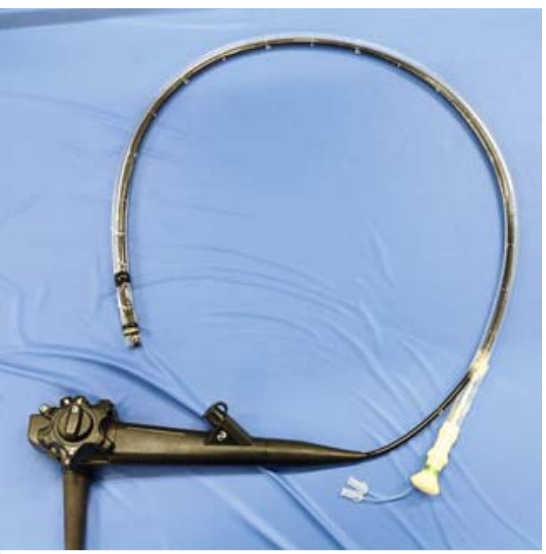

- Fig. 1 The suction equipment used for this procedure, which includes a nasal endoscope and overtube.

The presence of gastrointestinal blood clots and food residue often makes emergent endoscopic procedures difficult $[1,2]$. Removal procedures are conventionally performed using grasping forceps, but these techniques require long procedure times and leave behind large amounts of residue. Although a tube-assisted suction method has been recently reported [3], the ability to pass through a narrow space and the adequacy of suction with side-scope navigation seem limited due to poor followability. For this reason, we developed a novel method of gastrointestinal residue removal using existing instruments.

We conducted an experimental study on two beagle dogs with food jelly filling the upper and middle stomach ( $\triangleright$ Video 1 ). The equipment used consisted of a balloon overtube (TS-12140; Fujifilm, Tokyo, Japan) and a small-caliber endoscope (EG-L580NM7; Fujifilm) ( $\triangleright$ Fig. 1). First, a $10 \times 10-\mathrm{mm}$ cross-shaped incision was made at the base of the overtube ( $\vee$ Fig. 2 ), and the endoscope was fixed $2 \mathrm{~mm}$ from the distal tip of the overtube through the incision hole and connected

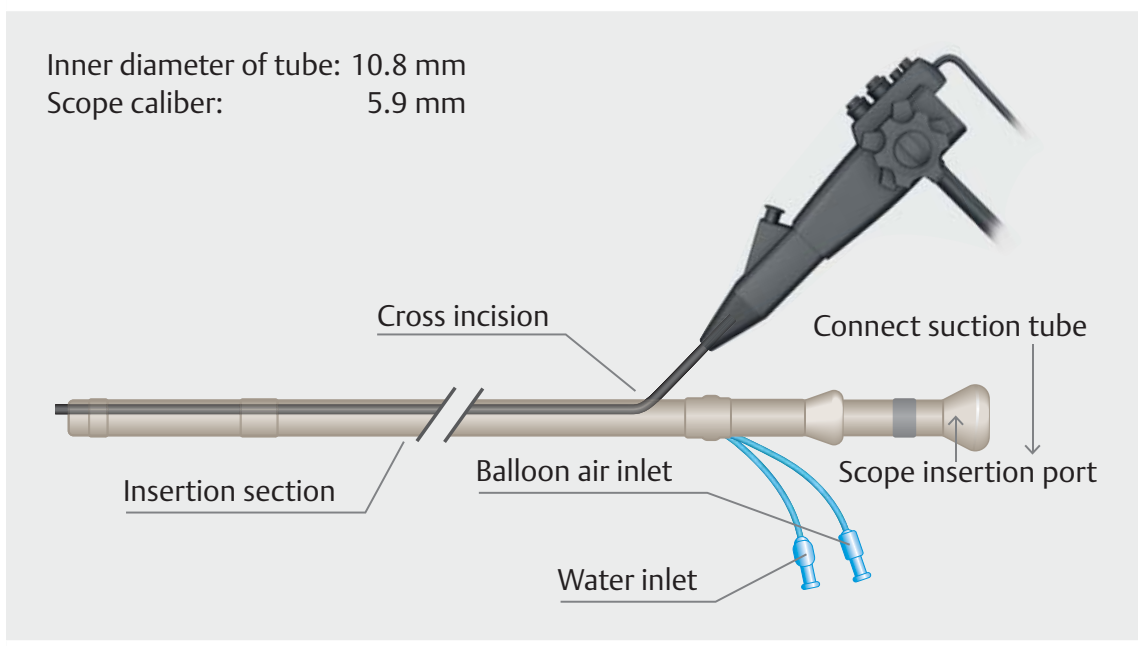

- Fig. 2 Detailed schematic of the equipment, including the suction channel with a 4.9-mm maximum diameter. The endoscope was inserted through the $10 \times 10$-mm cross-shaped incision at the base of the overtube.

at four points using silk thread ( $\triangleright$ Fig. 3 ). The maximum diameter of the suction channel was $4.9 \mathrm{~mm}$, which is larger than the 3.2-mm forceps channel in a conventional endoscope. Next, the overtube was inserted into the stomach under visual observation via the endoscope. With this configuration, large amounts of residue were effectively aspirated through the channel (\$Fig.4). Suctioning the superficial mucosa, which is unavoidable unless preventive measures are taken, interrupts the smooth suctioning procedure. We therefore found it useful to push the mucosa using a biopsy forceps to maintain a clear view throughout the procedure (\$Fig.5). This procedure was successful in creating a clear operation field without any complications in both animals. The procedure time was 6 min on average.

This experiment demonstrates that this novel method may be efficient for removing upper gastrointestinal residue.

Endoscopy_UCTN_Code_TTT_1AO_2AN

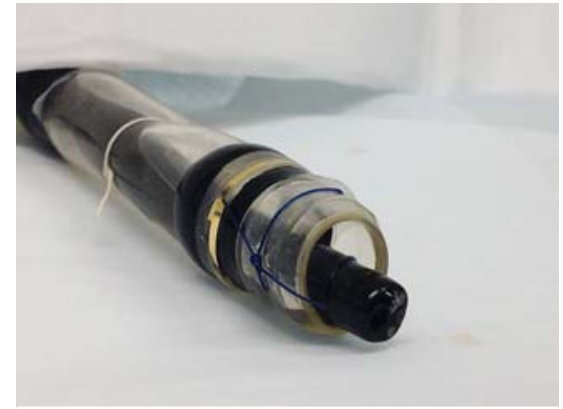

$\checkmark$ Fig. 3 The endoscope was fixed $2 \mathrm{~mm}$ from the distal tip of the overtube and connected to the overtube at four points using silk thread.

\section{Competing interests}

The authors declare that they have no conflict of interest. 


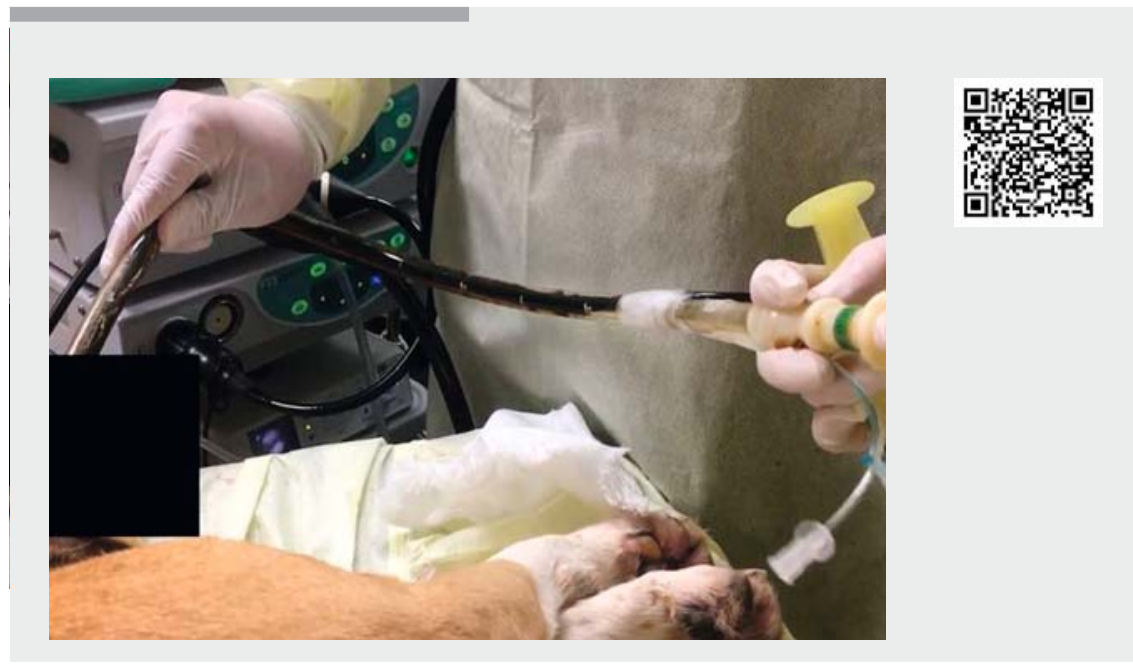

$\checkmark$ Video 1 Suction equipment and procedure for the proposed novel, rapid, and safe method of removing upper gastrointestinal residue.

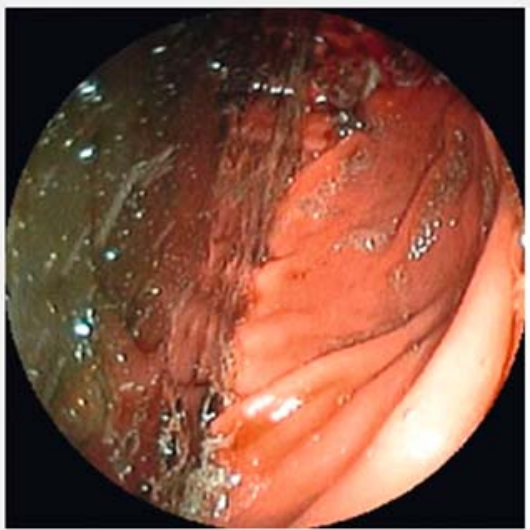

a

Before removing residue

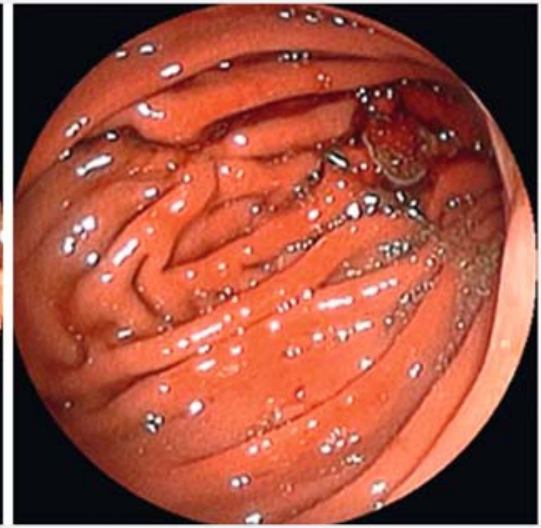

After removing residue

Fig. 4 Endoscopic images showing the operation field before and after the suction method was applied: $\mathbf{a}$ before, $\mathbf{b}$ after.

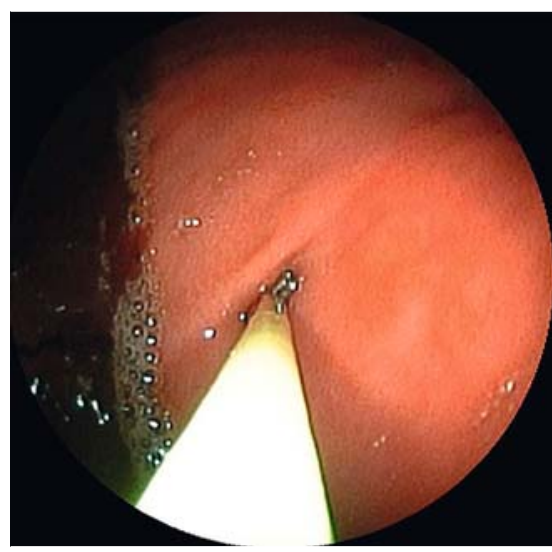

The authors

Kazuhiro Kozuka, Hideki Kobara, Noriko Nishiyama, Taiga Chiyo, Nobuya Kobayashi, Tatsuo Yachida, Tsutomu Masaki

Department of Gastroenterology and Neurology Faculty of Medicine, Kagawa University, Miki, Kita, Kagawa, Japan
Corresponding author

\section{Kazuhiro Kozuka, MD}

Department of Gastroenterology and Neurology, Faculty of Medicine, Kagawa University, 1750-1 Ikenobe, Miki, Kita, Kagawa 761-0793, Japan

Fax: +81-87-8912158

koduka2525@gmail.com

\section{References}

[1] Coleski R, Baker JR, Hasler WL. Endoscopic gastric food retention in relation to scintigraphic gastric emptying delays and clinical factors. Dig Dis Sci 2016; 61: 2593-2601

[2] Watanabe H, Adachi W, Koide $\mathrm{N}$ et al. Food residue at endoscopy in patients who have previously undergone distal gastrectomy: risk factors and patient preparation. Endoscopy 2003; 35: 397-401

[3] Zeng X, Yan P, Ye L et al. Tube-assisted suction: a novel technique for removing massive food residue during gastroscopy. Endoscopy 2019; 51: E73-E74

\section{Bibliography}

Endoscopy 2021; 53: E130-E131

DOI 10.1055/a-1216-0216

ISSN 0013-726X

published online 5.8.2020

(c) 2020. Thieme. All rights reserved.

Georg Thieme Verlag KG, Rüdigerstraße 14, 70469 Stuttgart, Germany

\section{ENDOSCOPY E-VIDEOS}

https:/|eref.thieme.de/e-videos

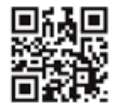

Endoscopy E-Videos is a free access online section, reporting on interesting cases and new

techniques in gastroenterological endoscopy. All papers include a high quality video and all contributions are freely accessible online.

This section has its own submission website at

https://mc.manuscriptcentral.com/e-videos

Fig. 5 Pushing the mucosa using a biopsy forceps was useful to maintain a continuously clear view. 